\title{
CLINICOETIOLOGICAL EVALUATION OF THE PATIENTS OF MACROCYTIC ANEMIA PRESENTING AT A TERTIARY CARE CENTRE IN KUMAON REGION OF UTRRAKHAND
}

KEY WORDS: macrocytic anemia, vitamin B12
Harish Chandra Arya

\section{Ashok Kumar*}

Junior Resident, Department Of Medicine, Resident Hostel Government Medical College Haldwani Uttrakhand.

Associate professor, Department of medicine, Government Medical College Haldwani Uttrakhand. *Corresponding Author

INTRODUCTION: Macrocytosis is common in various clinical settings and it is found in approximately $1.7-3.6 \%$ of people admitted for care for any cause $[1,2,3]$. Macrocytic anemia is generally classified as megaloblastic or nonmegaloblastic anemia. The causes of macrocytosis fall into two groups: (a) deficiency of vitamin B12 (cobalamin) or folate (or rarely abnormalities of their metabolism) in which the bone marrow is megaloblastic and (b) other causes, in which the bone marrow is usually normoblastic. A high level of suspicion, proper elicitation of the history and thorough examination and investigation of the patient helps in the diagnosis of macrocytic anemia.

AIM AND OBJECTIVES: To evaluate the etiology of macrocytic anemia at a tertiary care centre. To determine the etiology of macrocytic anemia. To evaluate clinical manifestations associated with macrocytic anemia.

MATERIAL AND METHOD: This 21 month Cross sectional observational study was carried out in OPD/IPD Department of Medicine, Government Medical College Haldwani (Uttarakhand). Full clinical examination and information regarding alcohol intake, dietary habit, drug intake, thyroid disorder and other comorbid illnesses was obtained. All patients were investigated with a completeHaemogramLiver function tests Serum TSH fasting vitamin B12 was measured Ultrasound as and when required.

RESULT: In this study 106 patients were taken 58 (45.3\%) were male and 48(54.7\%) were females. Mean age was $44.83+16.85$ years. Hemoglobin and MCV was in the range of $6.42 \pm 2.09,(108.24 \pm 7.10)$ respectively . The majority of patient, $28(52.83 \%)$ had vit B12 level in the range of $101-200 \mathrm{pg} / \mathrm{ml}$, The majority of patients, $44(41.1 \%)$ had LDH level in the range of $281-1000 \mathrm{IU} / \mathrm{L}$.

CONCLUSION: In this study, there was a preponderance of young people. Vegetarians were most susceptible to MA especially cobalamin deficiency. Nutritional deficiency was the most common cause of MA, followed by alcohol and alcoholic liver disease. Data regarding the magnitude of the problem in different parts of India and the factors that might influence its incidence were lacking. Macrocytic anemia must be considered in the differential diagnosis of patients presenting with pyrexia of unknown origin, mild icterus or pancytopenia.

\section{INTRODUCTION}

Macrocytosis is common in various clinical settings and it is found in approximately $1.7-3.6 \%$ of people admitted for care for any cause ${ }^{[1,2,3]}$. Heterogeneous group of disorders acting via various known and unknown processes can lead to macrocytic anemia. Macrocytic anemia is generally classified as megaloblastic or non-megaloblastic anemia.

Macrocytosis is a rise in the mean cell volume of the red cells above the normal range $\{$ in adults $8095 \mathrm{fl}$ (femtolitres)\}. The mean cell volume is lower in children than in adults, with a normal mean of $70 \mathrm{fl}$ at age 1 year, rising by about $1 \mathrm{fl}$ each year until adult volumes are reached at puberty. The causes of macrocytosis fall into two groups: (a) deficiency of vitamin B12 (cobalamin) or folate (or rarely abnormalities of their metabolism) in which the bone marrow is megaloblastic and (b) other causes, in which the bone marrow is usually normoblastic.In other causes of macrocytosis, other hematological abnormalities are usually presentin myelodysplasia, pure red cell aplasia may also cause macrocytosis. Paraproteinemia may cause a rise in mean cell volume without macrocytes being present in the blood film.Physiological causes of macrocytosis are pregnancy and the neonatal period. Drugs that affect DNA synthesis for example, hydroxyurea and azathioprine can cause macrocytosis with or without megaloblastic changes. Finally, a rare benign familial type of macrocytosis has been described.

An increased value of MCV, among various other findings at regular laboratory investigations, might be the early feature of various disease states like low vitamin B12 or low folate levels, pre leukemia, drug induced or alcoholism ${ }^{[4]}$. Schilling test shows impaired absorption of the vitamin in pernicious anemia; this can be corrected by giving intrinsic factor.
Endoscopy should be performed to confirm atrophic gastritis and exclude gastric carcinoma or gastric polyps. Bone marrow is required for the diagnosis of myelodysplasia, aplastic anemia, myeloma and other marrow disorders associated with macrocytosis. If folate deficiency is diagnosed, it is important to assess the dietary folate intake and to exclude gluten induced enteropathy by endoscopy and duodenal biopsy. The deficiency is common in patients with diseases of increased cell turnover whoalso have a poor diet.

Macrocytic anemia can be wrongly diagnosed as iron deficiency anemia in many situations The diagnosis of megaloblastic anemia is offered only when there is no response to iron supplementation after a latent period.

A high level of suspicion, proper elicitation of the history and thorough examination of the patient helps in the diagnosis of macrocytic anemia. A search for and identification of distinct clinical features may help in the diagnosis of macrocytic anemia and in the early identification of low levels of B12 or folicacid.

\section{AIM AND OBJECTIVES:}

- To evaluate the etiology of macrocytic anemia at a tertiary care centre.

- To determine the etiology of macrocytic anemia.

- To evaluate clinical manifestations associated with macrocytic anemia.

\section{Inclusion Criteria:}

- Age $>16$ years

- $\mathrm{Hb}<10 \mathrm{gm} / \mathrm{dl}$

- MCV > 100fl

- Macrocytosis on peripheral smear 


\section{Exclusion Criteria:}

- Patients who were recently transfused blood.

- Patients who were on vit B12 therapy.

- Patients with macrocytic anemia not willing to participate.

\section{MATERIAL AND METHODS}

The present study was hospital based Cross sectional observational study carried out on 106 patients at OPD/IPD Department of Medicine, Government Medical College and associated Dr. Susheela Tiwari Hospital, Haldwani (Uttarakhand) during study period JANUARY 2019 to SEPTEMBER 2020.

Detailed history was obtained from the patients. Full methodical clinical examination was done in all patients. Complete information was obtained regarding alcohol intake, dietary habit, drug intake, thyroid disorder and other comorbidillnesses.

All patients were investigated with a complete Hemogram Liver function test, Serum TSH, and Patients' fasting vitamin $\mathrm{B}_{12}$ was measured. Ultrasound was done as and when required. Upper gastrointestinal endoscopywas done in patients with megaloblastic anemia who consented for the procedure.

\section{OBSERVATION AND RESULTS}

Observation were drawn from study population of 106 patients presenting with macrocytic anemia 58 were males comprising about $45.3 \%$ and 48 were females comprising about $54.7 \%$.

Majority of patients (20.8\%) belonged to age group 4655years followed by $26-45$ years constituting $17.9 \%$ of patients. The mean age was $44.83+16.85$ year.

None of the patients in the study belonged to class I of socioeconomic status, class III constituted maximum no. of participants, 33 (31.4\%) followed by class IV constituting 27 $(25.5 \%)$ of patients.

Maximum number of patients, 89 (84\%) were non-vegetarian by diet habit while there were $17(16 \%)$ vegetarian patients in thestudyIn our study 54 (51\%) patients were from tarai region, $33(31 \%)$ were from hilly region and $19(18 \%)$ were from plain region.

Most patients were 75 (70.8\%) patients were nonalcoholic while $31(29.2 \%)$ were alcoholic Majority of patients $86(81.13 \%)$ had no history of drug intake, 8 patients were on metformin, 4 patients on antiretroviral therapy, 3 patients each were taking NSAIDS and other drugs.

Most of patients were not known to have any autoimmune disease 8 patients had diabetes mellitus followed by 1 patient each having psoriasis and rheumatoid arthritis as diagnosis.

Majority of patients $86(81.1 \%)$ had fatigue as presenting complaint while 71 patients had breathlessness, 63 had loss of appetite, 42 had fever, 36 had vomiting, 35 had yellow discoloration of sclera, 33 had neurological manifestations, 26 had bleeding manifestations, 27 had abdominal pain, 23 had swelling of feet, 15 had oral ulcer, 14 had diarrhea, 16 had palpitations, and 11 had weight loss.

On analysis of the hematological parameters, hemoglobin was in the range of $6.42 \pm 2.09$, followed by total count (7375 \pm $6907)$, platelet count (123686 \pm 100097$)$, PCV (19.89 \pm 6.38$)$, reticulocytecount $(2.08 \pm 2.31), \mathrm{MCV}(108.24 \pm 7.10), \mathrm{MCH}$ (34.78 \pm 4.08$), \mathrm{MCHC}(32.36 \pm 2.77)$.

Majority of patients (61)in present study were having hemoglobin in the range of $4.1-8 \mathrm{gm} / \mathrm{dl}$, followed by 18 patients with hemoglobin in the range of $1.6-4 \mathrm{gm} / \mathrm{dl}$.
Majority of patients $28(52.83 \%)$ hadVit Bl2 level in the range of $101-200 \mathrm{pg} / \mathrm{ml}$, while $9(16.98 \%)$ patients hadVit B12 level in the range of $<100 \mathrm{pg} / \mathrm{ml}$.

Majority of patients $44(41.1 \%)$ had LDH level in the range of $281-1000 \mathrm{IU} / \mathrm{L}$ and $\geq 1000 \mathrm{IU} / \mathrm{L}$, while $18(16.8 \%)$ patients had level in the range of $\leq 280 \mathrm{IU} / \mathrm{L}$.

On upper GI endoscopy 5 patients had oesophageal varices, 5 patients had portal gastropathy, 3 had erosive gastritis while 1 patients had malloryweiss tear as diagnosis .

In our study 12 patients had altered echotexture of liver as finding followed by splenomegaly and hepatomegaly in 8 and 7 patients respectively.

According to the basis of etiological classification of macrocytic anemia, on evaluating 106 patients we found $37(34.90 \%)$ had Vit Bl2 deficiency, chronic alcoholism in 20 $(18.86 \%)$, chronic liver disease in $8(7.54 \%)$, haemolysis/ haemorrhagein $7(6.60 \%)$, chronic kidney disease in $4(3.77 \%)$, drug induced anemia in $3(2.83 \%)$, acute myeloid leukemia in $2(1.88 \%)$, hypothyroidism in $3(2.83 \%)$, pregnancy in $3(2.83 \%)$; in 19 (17.92\%) cases the etiology was unknown.

According to the basis of etiological classification of macrocytic anemia, on evaluating 106 patients we found $37(34.90 \%)$ had Vit Bl2 deficiency, chronic alcoholism in 20 (18.86\%), chronic liver disease in 8 (7.54\%), haemolysis/ haemorrhagein $7(6.60 \%)$, chronic kidney disease in $4(3.77 \%)$, drug induced anemia in $3(2.83 \%)$, acute myeloid leukemia in $2(1.88 \%)$, hypothyroidism in $3(2.83 \%)$, pregnancy in $3(2.83 \%)$; in 19 (17.92\%) cases the etiology was unknown.

\section{DISCUSSION}

Macrocytic anemia is one of the preventable and treatable causes of nutritional anemia.Macrocytic anemia is either due to Vitamin B12 deficiency or folate deficiency or both.Folic acid and Vitamin Bl2 are essential dietary components for humans because they are required for DNA synthesis. Hematopoietic cells (having a very high turnover) are especially sensitive to deficiencies of folate and vitamin B12. With derangement of DNA synthesis due to deficiencies of these vitamins, megaloblastic anemia ensues ${ }^{[22]}$.

\section{Sociodemographic Features}

In our study population of 106 patients presenting with macrocytic anemia, 58 were males comprising about $45.3 \%$ and 48 were females comprising about $54.7 \%$. Comparing the gender ratio with other studies, the study by Vineetha Unnikrishnan et $a l^{[7]}$ showedmale predominance.

But studies done by Tejas Shah et al and Uma Khanduri et al showed femalepredominance.

The majority of the patients $(20.8 \%)$ belonged to the age group of 46-55 years followed by 26-45 years constituting $17.9 \%$ of patients. The mean age was $44.83+16.85$ years.

In comparison, Salma Haq et al ${ }^{[9]}$ study showed $17.6 \%$ of patients in the age group $41-60$ years and $12.5 \%$ in the age group above 60 years. In contrast to our study, this study also included patients below the age of $15 y e a r s$.

In our study $89(84 \%)$ of the patients were on mixed diet and $17(16 \%)$ were on vegetarian diet and non-vegetarians were commonly found to be affected. In concordance with our study, the study conducted by Iqbal SP et al ${ }^{[13]}$ showed Vitamin B12 deficiency in $94 \%$ of non- vegetarians. The data collected from Andrews $L$ et $a l^{[122]}$ and SR Kankonkar et $a I^{[14]}$ showed that vitamin B12 deficiency is higher in vegetarians compared to non-vegetarians. 
None of the patients in our study belonged to class I of socioeconomic status; class III constitutes the maximum no of participants- $33(31.4 \%)$ followed by class IV constituting 27 $(25.5 \%)$ of patientsMajority of the patients- $97(91.5 \%)$ were Hindu by religion followed by Muslim constituting 7 (6.6\%) patients. Unnikrishnan et $a l^{[7]}$ found $96 \%$ patients $(25 / 26)$ of MA were from the Hindu community and $4 \%$ (1/26) from the Muslim community. Hindu Indians are usually strict vegetarians and are more prone to develop nutritional anemia. Matthews and Wood ${ }^{[16]}$ had studied the incidence of MA in Asians and found $95 \%$ patients from the Hindu community and 5\% from the Muslim community, similar to our study.

In our study, $54(51 \%)$ patients were from tarai regions, $33(31 \%)$ were from hilly areas and $19(18 \%)$ were from plain regions. Majority of patients were literate- 77 (72.6\%) while only $29(27.4 \%)$ were illiterate. No other study was found which compared the residential area of patients.

The maximum75 (70.8\%) patients were nonalcoholic while $31(29.2 \%)$ were alcoholic.Alcoholism is a well-known cause of macrocytic anemia. Chronic consumption of more than 80 grams of alcohol per day has adverse effects on the hematologic system ${ }^{[24]}$. Even before anemia develops, approximately $90 \%$ of alcoholics have macrocytosis (MCV between 100 and $110 \mathrm{fL})^{[25]}$. Diagnosing alcoholism is often difficult, but the Michigan Alcoholism Screening test and glutamyl transferase levels are found to be the two most sensitive tests for detecting alcoholism in patients with macrocytosis ${ }^{[132]}$. In patients with elevated MCV, it may be valuable to perform the above tests, taking into consideration the possibility of alcoholism. Abstinence from alcohol rapidly returns elevated MCV to normal levels ${ }^{[26]}$.

The majority of patients- $86(81.13 \%)$ had no history of drug intake, 8 patients were on metformin, 4 patients on antiretroviral therapy, 3 patients each taking NSAIDS and thyroxin. Anticonvulsants, sulfasalazine, anti-retroviral drugs, folate antagonists, chemotherapeutic agents, pyrimethamine, sulfamethoxazole, metformin, trimethoprim are some of the known drugs causing macrocytosis ${ }^{[21,22]}$.Most patients with HIV being treated with reverse transcriptase inhibitors willdisplay macrocytosiswithout anemia. In these patients, macrocytosis is considered a surrogate marker indicating the patient's compliance in taking medication ${ }^{[21]}$.

\section{PRESENTING SYIMPTOMS AND SIGNS}

In the study by $T e j a s$ Shah et $a l^{[10]} 63 \%$ had pallor, $32 \%$ had skin hyperpigmentation and $12 \%$ had icterus. In the study by Salma Haq et $a l^{[9]} 84 \%$ had pallor, $28 \%$ had jaundice and hepatomegaly and $48 \%$ percent had splenomegaly. In a study by Vineetha Unnikrishnan ${ }^{[7]} 35 \%$ had jaundice, $31.7 \%$ had splenomegaly, $28.3 \%$ had hepatomegaly and $23.3 \%$ had skin changes. when compared to the above studies our study population had higher percentage of patients with pallor $(98 \%)$ and icterus $(32.1 \%)$, and slightly lower number of patients with skin changes $(20.8 \%)$, hepatomegaly $(24.6 \%)$ and splenomegaly $(15.09 \%)$. Lindenbaumet al ${ }^{[17]}$ found in their study that patients with cobalamindeficiency present with neuropsychiatric symptoms in $28 \%$ of cases, comparable to our result which is (31.1\%).

In our study majority of patients- $86(81.1 \%)$ had fatigue as presenting complaint while 71 patients had breathlessness, 63 had loss of appetite, 42 had fever, 36 had vomiting, 35 had yellow discoloration of sclera, 33 had neurological manifestations, 26 had bleeding manifestations, 27 had abdominal pain, 23 had swelling of feet, 15 had oral ulcers, 14 had diarrhea, 16 had palpitations, and 11 had weight loss as presenting complaint.While in a study by Deepankar $P^{[8]}$,pallor was the most common finding in the study group and present in $96 \%$ patient, skin hyperpigmentation was present in $48 \%$ and oral ulcer in $26 \%$ of patients. Fever was the presenting clinical finding in $34 \%$ patients. Other common clinical signs in the study were pedal edema (25\%), icterus (16\%), and lymphadenopathy (8\%).

\section{LABORATORY INVESTIGATION}

On laboratory investigation, thehematological parameter hemoglobin was in the range of $6.42 \pm 2.09 \mathrm{~g} / \mathrm{dl}$, followed by total count (7375 $\pm 6907 /$ cumm), platelet count (123686 \pm $100097 / \mathrm{cumm}), \mathrm{PCV}(19.89 \pm 6.38 \%)$, retic count $(2.08 \pm 2.31$ $\%), \operatorname{MCV}(108.24 \pm 7.10 \mathrm{fl}), \mathrm{MCH}(34.78 \pm 4.08 \mathrm{pg} / \mathrm{cell}), \mathrm{MCHC}$ $(32.36 \pm 2.77 \mathrm{~g} / \mathrm{dl})$. A total of $6 \mathrm{l}$ patients had hemoglobin in the range of $4.1-8 \mathrm{gm} / \mathrm{dl}$, followed by 18 patients in the range of $1.6-4 \mathrm{gm} / \mathrm{dl}$. Thrombocytopenia was detected in $72.20 \%$ patients. Khanduri et $\mathrm{ll}^{[5]}$ in their study reported $\mathrm{MCV}$ ranged from 77 to 123 and reticulocyte count was found to be higher (more than 2) in $42 \%$ case. Chanarinet $\mathrm{al}^{[18]}$. described $60 \%$ of patients with $\mathrm{Hb}<10,84 \%$ of patients with raised MCV level.In the study by Deepankar $\mathrm{P}$ et $\mathrm{al},{ }^{[8]}$ mean hemoglobin value of study group was $7.16 \pm 2.41$ (female -6.40 and male - 7.46). $88 \%$ of the participants had $\mathrm{Hb}$ level $<10 \mathrm{~g} / \mathrm{dL}$, and $11 \%$ cases had value more than $10 \mathrm{~g} / \mathrm{dL}$, and $53 \%$ of the patients had value of $<6 \mathrm{~g} / \mathrm{dL}$. On presentation, in our study population a majority of50 patients $(47.16 \%)$ had bicytopenia, while 30 (28.30) had pancytopenia. The study by Tejas Shah et $\mathrm{al}^{[12]}$ reported same percentage $(48 \%)$ of patient with pancytopenia. In another study by Uma Khandhuri et $\mathrm{al}^{[12]}$ pancytopenia was reported in $62 \%$ of patients. The study by Salma Haq et $\mathrm{al}^{[9]}$ reported pancytopenia in $41 \%$ and bicytopenia in $60 \%$.

\section{Vit B12 level:}

In our study,the majority of patients 28 (52.83\%) had vit Bl2 level in the range of $101-200 \mathrm{pg} / \mathrm{ml}$, while $9(16.98 \%)$ patients had levels in the range of $<100 \mathrm{pg} / \mathrm{ml}$.Khanduri et $\mathrm{al}^{[34]}$ reported cobalamin deficiency in 65\%, FA deficiency in $23 \%$, and combined deficiency in $12 \%$ of cases. Moreover, Unnikrishnan et al ${ }^{[7]}$ reported cobalamin in $69 \%$ cases and FA deficiency in $19 \%$ cases in their study. Results of these studies regarding relative prevalence of cobalamin and FA deficiency were comparable to our result.

In our study majority of the patients, $44(41.1 \%)$ had LDH level in the range of $281-1000 \mathrm{IU} / \mathrm{L}$ and $\geq 1000 \mathrm{IU} / \mathrm{L}$, while 18 $(16.8 \%)$ patients had level in the range of $\leq 280 \mathrm{IU} / \mathrm{L}$. Jaswal et. al. ${ }^{[30]}$ stated that raised serum $\mathrm{LDH}$ levels were seen in all types of macrocytic anaemia, but serum total $\mathrm{LDH}$ values $>3000 \mathrm{IU} / \mathrm{L}$ are diagnostic of megaloblastic anaemia and values between 451-3000 IU/L can be seen in megaloblastic anaemia with early megaloblastic change, dimorphic anaemia and hemolytic anemia.

On upper GI endoscopy 5 patients had oesophageal varices, 5 patients had portal gastropathy, 3 had erosive gastritis while 1 patient had malloryweiss tear as diagnosis. Similar study by Kotli Nagaraj et $\mathrm{al}^{[27]}$ found Upper GI endoscopy was normal in 46 patients $(61.3 \%)$, gastritis and gastric atrophy was seen in $17(22.6 \%)$ and $12(16 \%)$ patients respectively. In contrast, in the same study by Nafil $\mathrm{H}$, et $\mathrm{al}^{[28]}$ gastritis was the most common finding and was seen in $82.7 \%$ of the study population.

Ultrasonography findings reported 12 patients with altered echotexture of liver followed by splenomegaly and hepatomegaly in 8 and 7 patients respectively.

A study from north-west India by Sarode R et al has found 34\% of megaloblastic anemia is associated with mild splenomegaly. Few studies have shown association of pernicious anemia with giant splenomegaly.

A study by Khan FS et al. demonstrated the different aetiologies of pancytopenia based on bone marrow examination and found $13.2 \%$ cases of megaloblastic anemia as aetiology and $37.2 \%$ splenomegaly as clinical association. 


\section{ETIOLOGY}

In our study according to the basis of etiological classification of macrocytic anemia, on evaluating 106 patients we found $37(34.90 \%)$ had Vit B12 deficiency, Chronic alcoholism in 20 (18.86\%), Chronic liver diseasein 8 (7.54\%), Haemolysis/ haemorrhagein $7(6.60 \%)$, Chronic kidney disease in $4(3.77 \%)$, Drug induced in $3(2.83 \%)$, Acute myeloid leukemia in $2(1.88 \%)$, Hypothyroidism in $3(2.83 \%)$, Pregnancy in $3(2.83 \%)$; in 19 (17.92\%) cases the etiology was unknown. Similar to our study Unnikrishnan et $\mathrm{al}^{[7]}$ reported nutritional deficiency in $26 \%$ cases and alcohol abuse in $13 \%$ cases as etiological factors for MA. Britt et $\mathrm{al}^{[19]}$ studied MA among Indians in Britain and found $68 \%$ cases of nutritional deficiency, $12 \%$ cases of pernicious anemia, and $20 \%$ cases of malabsorption. However, they did not mention the etiology of malabsorption.

\section{CONCLUSION}

In our study, there was a preponderance of young people. Hindu community was most commonly affected. Vegetarians especially vegans were most susceptible to MA especially cobalamin deficiency. The pathological conditions associated with the MA were much diverse. Nutritional deficiency was the most common cause of MA, followed by alcohol and alcoholic liver disease.Macrocytic anemia causedsubstantial morbidity in patients with anemia. Data regarding the magnitude of the problem in different parts of India and the factors that might influence its incidence were lacking. Macrocytic anemia must be considered in the differential diagnosis of patients presenting with pyrexia of unknown origin, mild icterus or pancytopenia. Documentation of occult cobalamin deficiency in different ethnic and socioeconomic groups and in pregnant women needs to be done. Although the number of patients undergoing investigation were less, yet the improvement in the quality of life of patients undergoing treatment after ascertaining the type of anemia and etiology of macrocytic anemia helped us to establish further management of the patients. The early screening for cobalamin and folic acid deficiency of patients with minor symptoms of anemia can lead to improvement in the wellbeing and prolongs the life of people in our community.

\section{LIMITATIONS}

The following were the limitations of the study

- In patients who presented with nutritional deficiency complete work up of malabsorption like stool examination for ova and cyst, quantitative assay of stool fat, d-xylulose test, and biopsy were not done atall.

- Bone marrow trephine biopsy could not be done. Thus, a comprehensive approach had to be adapted.

- Since our sample size was small we could not find conclusive evidence of certain hematological parameters on the basis of which vitamin B12 deficiency could be differentiated from folic acid deficiency and extensive work up could also not be done.

- The study was done in a tertiary care hospital and only patients with macrocytic anemia were included. Henceforth, quite a few number of patients with vitamin B12 and folate deficiency who did not have anemia might have been missed.

\section{CONFLICT OF INTREST: NONE}

\section{REFERENCES:}

1. GR L, Foerster J, Lukens J, Paraskevas F, Greer JP RG. Anemia: A Diagnostic Strategy. 10th ed. (Wintrobe MM, ed.).; 1998:908-940.

2. McPhedran P, Barnes MG, Weinstein JS, Robertson JS. Interpretation of electronically determined macrocytosis. Ann Intern Med.1973;78(5):677-83.

3. Davidson RJ, Hamilton PJ. High mean red cell volume: its incidence and significance in routine haematology.J Clin Pathol. 1978;31 (5):493-8.

4. Breedveld FC, Bieger R, van Wermeskerken RK. The clinical significance of macrocytosis.Acta Med Scand.1981;209(4):319-22.

5. Carmel R. Macrocytosis, mild anemia, and delay in the diagnosis of pernicious anemia. Arch Intern Med.1979;139(1):47-50.

6. Khanduri U, Sharma A, Joshi A. Occult cobalamin and folate deficiency in Indians. Natl Med J India 2005; 18:182-3.
7. Mandloi R. Clinico-Haematological and Biochemical Profile of Megaloblastic Anemia.jmscr [Internet].2018 Aug 30 [cited 2020 Nov 22];6(8).

8. Kannan A, Tilak V, Rai M, Gupta V. Evaluation of clinical, biochemical and hematological parameters in macrocytic anemia. Int J Res Med Sci. 2016;2670-8.

9. Khanduri U, Sharma A. Megaloblastic anaemia: Prevalence and causative factors. THE NATIONAL MEDICAL JOURNAL OF INDIA. 2007;20(4):4.

10. Iqbal SP, Kakepoto GN, Iqbal SP. Vitamin B12 deficiency--a major cause of megaloblastic anaemia in patients attending a tertiary care hospital. J Ayub Med Coll Abbottabad. : 4

11. Kankonkar SR, Joshi SV,Tijoriwala SJ, et al. A study of vitamin B12 deficiency of different diseases. Bombay Hospital Journal. 2004;46.

12. Liggy A, Thomas T, Nambudiri H. vitamin B12 status in a tertiary care center in central gujarat.3(3):3.

13. Matthews JH,Wood JK. Megaloblastic anaemia in vegetarian Asians. Clin Lab Haematoll $984 ; 6: 1-7$

14. Lindenbaum J, Healton EB, Savage DG, Brust JC, Garrett TJ, Lindenbaums J, et al. Neuropsychiatric disorders caused by cobalamin deficiency in the absence of anemia or macrocytosis. N Engl J Med 1988;318:1720-8.

15. Niazi M, Khan MT. Clinical and hematological features of megaloblastic anaemia alone or in combination with iron deficiency anemia- an analysis of 349 patients.J Med Sci 2009;17:81-4.

16. Chanarin I, Malkowska V, O'Hea AM, Rinsler MG, Price AB. Megaloblastic anemia in a vegetarian Hindu community. Lancet 1985;2:1 168-72.

17. Britt RP, Harper C, Spray GH. Megaloblastic anemia among Indians in Britain. QJ Med 1971;40:499-520.

18. Maktouf C, Bchir A, Louzir H, Mdhaffer M, Elloumi M, Ben Abid H, et al. Megaloblastic anemia in North Africa. Haematologica2006;91:990-1.

19. Kaferle J and Strzoda CE. Evaluation of macrocytosis. Am Fam Physician 2009;79(3):203-208.

20. Conigrave KM, Haber P,Whitfield JB. Traditional markers of excessive alcohol use.Addiction 2013;98(2):31-43.

21. Thomas, Anand P, Suman R, Maria L, Swarnarekha B. Megaloblasticanemia- A clinical spectrum and a hematological profile. ISSN 0973-0958, 2006; 11 (3).

22. Seppa K, Laippala P, Saarni M. Macrocytosis as a consequence of alcohol abuse among patients in general practice. Alcohol. Clin. Exp. Res. 15(5), 871-876 (1991)

23. Nagao T, Hirokawa M. Diagnosis and treatment of macrocytic anemias in adults. J Gen Fam Med.2017 Oct:18(5):200-4

24. Hoffbrand V, Provan D. ABC of clinical haematology. Macrocytic anaemias. BMJ 1997;314:430.

25. Seppä K, Sillanaukee P, Saarni M. Blood count and hematologic morphology in nonanemic macrocytosis: differences between alcohol abuse anpernicious anemia. Alcohol 1993;10:343-7.

26. Maruyama S, Hirayama C,Yamamoto S, et al. Red blood cell status in alcoholic and non-alcoholic liver disease. J Lab Clin Med 2001;138:332-7.

27. Shipton MJ, Thachil J. Vitamin B12 deficiency-A21st century perspective. ClinMed (Lond). 2015;15:145-50.

28. Carmel R, Agrawal YP. Failures of cobalamin assays in pernicious anemia. N Engl JMed2012;367:385-6we

29. Kotli Nagaraj, Sagar Sourabh.Upper Gastrointestinal Endoscopic Findings in Patients withVitamin B12 Deficiency. International Archives of Integrated Medicine.2019 Apr;6(4):112-1

30. Nafil H, Tazi I, Sifessalam M, Bouchtia M, Mahmal L. Clinical, biological and therapeutic profile of anemia by vitamin B12 deficiency in the department of hematology of Marrakech, Morocco. Bull Soc PatholExot., 2013 May; 106(2): 83-88.

31. Zeldis, J. B., H. Mugishima, H. N. Steinberg, E. Nir, and R. P. Gale. 1986. In vitro hepatitis B virus infection of human bone marrow cells. J. Clin. Invest. 78:411417.

32. Jaswal TS, Mehta HC, Gupta V, Singh M, Singh S. Serum Lactate Dehydrogenase in diagnosis of megaloblastic anemia. Indian J. Pathol. Microbiol. 2000;43(3):325-9.

33. Edwards MJ, Penny RH. Effects of hyperthermia on the myelograms of adult and fetal guinea-pigs. BrJHaematol.1985;59(1):93-101. 